Article (refereed)

Taylor, Christopher M.; Gounou, Amanda; Guichard, Francoise; Harris, Phil P.; Ellis,

Richard J.; Couvreux, Fleur; De Kauwe, Martin. 2011 Frequency of Sahelian storm initiation enhanced over mesoscale soil-moisture patterns. Nature Geoscience, 4 (7). 430-433.

$\underline{10.1038 / \text { ngeo1173 }}$

Copyright @ 2011 Macmillan Publishers Limited

This version available http://nora.nerc.ac.uk/14104/

NERC has developed NORA to enable users to access research outputs wholly or partially funded by NERC. Copyright and other rights for material on this site are retained by the authors and/or other rights owners. Users should read the terms and conditions of use of this material at http://nora.nerc.ac.uk/policies.html\#access

This document is the author's final manuscript version of the journal article prior to the peer review process. Some differences between this and the publisher's version may remain. You are advised to consult the publisher's version if you wish to cite from this article.

www.nature.com/

Contact CEH NORA team at

noraceh@ceh.ac.uk

The NERC and CEH trade marks and logos ('the Trademarks') are registered trademarks of NERC in the UK and other countries, and may not be used without the prior written consent of the Trademark owner. 


\title{
Frequency of Sahelian storm initiation enhanced over mesoscale soil moisture patterns
}

Christopher M. Taylor ${ }^{a}$, Amanda Gounou ${ }^{b}$, Françoise Guichard ${ }^{b}$, Phil P. Harris ${ }^{a}$,

5 Richard J. Ellis ${ }^{a}$, Fleur Couvreux ${ }^{b}$, Martin De Kauwe ${ }^{c}$.

\author{
${ }^{a}$ Centre for Ecology and Hydrology, Wallingford, U.K. \\ ${ }^{\mathrm{b}}$ CNRM (CNRS and Météo-France), Toulouse, France \\ ${ }^{\mathrm{c}}$ Macquarie University, Sydney, Australia
}

10 Version submitted to Nature Geoscience 21 April 2011

Soil moisture can affect rainfall through its control on surface evapotranspiration, which in turn influences temperature and humidity in the lower atmosphere and the development of convective storms. This provides a potentially important feedback mechanism in regional climate whereby, for example, dry soils could suppress the initiation of storms, thus prolonging soil water deficits. Climate models have illustrated the importance of soil moisture feedbacks for weekly rainfall totals in semiarid regions ${ }^{1}$, though large variations exist between models in their depiction. Here we use satellite observations of cloud and land surface temperatures over West

20 Africa to demonstrate that the surface exerts a strong control on storm initiation through patches of soil moisture on length scales of approximately 10-40 kms. Such patterns induce local winds which favour the development of storms. Initiations are 
twice as likely above strong positive soil moisture gradients compared to uniform soils. We find that $37 \%$ of all initiations analysed occurred over the steepest $25 \%$ of

25 gradients, implying that the feedback may be important in determining annual rainfall totals. Similar feedbacks are likely throughout the semi-arid tropics, influencing drought frequency and crop yields in regions prone to climate variability and change.

This study focuses on the impact of soil moisture on rainfall in the Sahel, a semi-arid region bounded to the north by the Sahara desert and to the south by closed canopy

30 tropical forest. The region receives almost all its annual rain in the summer wet season associated with the northward excursion of Inter-Tropical Convergence Zone under the influence of the West African Monsoon². A strong seasonal cycle in vegetation peaks in September, about 3 weeks after the climatological peak in rainfall. The region experiences extreme droughts by global standards, with profound 35 consequences for the local population. Modelling studies have illustrated how rainfall anomalies induced by oceanic variability are amplified by a feedback with Sahelian soil moisture and vegetation ${ }^{3-5}$. Climate models suggest soil moisture feedbacks on time scales of days are relatively strong in the Sahel ${ }^{1}$, a fact supported by observational evidence $e^{6-7}$. However, it is unclear which atmospheric processes

40 control the strength, and even the sign of the feedbacks operating at different spatial scales.

Feedbacks are relatively easy to observe in the Sahel. There is strong natural variability in soil moisture on a daily time scale, driven by convective rain events, and followed by drying of the top centimetres of the soil. This soil moisture variability 45 induces strong variations in surface fluxes in the days after rain because of the sparseness of the vegetation ${ }^{8}$. Accurate estimates of rainfall and surface fluxes do not exist on the scales at which land-convection feedbacks operate, but satellite data 
can provide valuable proxies. The presence of cold cloud, in particular when organised into extensive Mesoscale Convective Systems (MCS), provides a means to examine relationships between convection and the land surface from a statistical perspective. These long-lived travelling systems produce $80-90 \%$ of the annual rain in the region ${ }^{9}$, and the seasonal total of MCS account for the difference between a wet and a dry year ${ }^{10}$. For characterising surface flux variability we use 2 independent proxies. Surface soil moisture estimates ${ }^{11}$ are available typically daily from a passive

55 microwave sensor with a footprint $\sim 40 \mathrm{~km}$. For finer spatial resolution, we exploit Land Surface Temperature (LST) data, available from geostationary satellite every 15 minutes under clear sky at a resolution of $3 \mathrm{~km}^{12}$. Sahelian soil wetting and drying cycles create strong anomalies in LST (henceforth LSTA) on a daily time scale. We use variability in daytime mean LSTA as a proxy for surface fluxes with negative

60 anomalies indicative of increased evaporation and reduced sensible heat flux. Some characteristics of spatial variability in LSTA are provided in the Supplementary Material (Figure S5). Aircraft measurements made during the African Monsoon Multidisciplinary Analysis (AMMA) campaign ${ }^{13-15}$ have demonstrated that gradients in LSTA coincide with horizontal gradients in the Planetary Boundary Layer at

65 wavelengths as low as $5-10 \mathrm{~km}^{13}$. They provided conclusive observational evidence that antecedent rain can generate mesoscale convergence zones, even at wavelengths of $20 \mathrm{~km}$, consistent with modelling studies ${ }^{16-21}$. These convergence zones are important for their potential impact on the development of moist convection, a feedback process observed for a single case during $\mathrm{AMMA}^{14}$.

70 We examined the impact of the land surface on the initiation of MCS using a dataset of 3765 storms, within a region $\sim 2.5$ million $\mathrm{km}^{2}\left(10^{\circ} \mathrm{W}-10^{\circ} \mathrm{E}, 10-20^{\circ} \mathrm{N}\right)$ for the 200610 wet seasons. We tracked convective cloud areas using commonly-adopted 
thresholds of brightness temperature and areal extent (see Methods). We defined an MCS initiation event when a cold cloud first appeared, prior to expansion into an

75 MCS. This definition allowed us to assess where deep convection was triggered relative to the underlying surface. Our study covers the afternoon-evening period (1200 to 2100 UTC) when over $80 \%$ of MCS are initiated ${ }^{22}$.

Figure 1 shows the number of MCS initiations identified as a function of land surface properties, on a regular grid of $0.35 \times 0.35^{\circ}$ (approximately $40 \times 40 \mathrm{~km}^{2}$ ). The

80 probability of initiation $\left(\mathrm{P}_{\mathrm{I}}\right)$ for different soil moisture conditions at this scale (Fig 1a) provides no clear evidence for a link between soil moisture and MCS initiation. However, a strong relationship emerges when one considers mesoscale anomalies in soil moisture (Fig 1b). Within an area of approximately $200 \times 200 \mathrm{~km}^{2}$, the size of a typical climate model grid box, the probability of storm initiation is about one third

85 higher over drier soils compared to wet areas. This relationship is consistent with previous studies looking at both Sahelian soil moisture ${ }^{6}$, and land cover in other regions $^{23-24}$, where afternoon convection is favoured over surfaces with a greater sensible heat flux.

To assess the relevance of finer-scale soil moisture patterns in the initiation process,

90 we examined the spatial variability of LSTA within each $40 \mathrm{~km}$ grid box by computing the standard deviation ( $\left.\sigma_{L S T A}\right)$ of the $3 \mathrm{~km}$ pixels within. The value of $P_{1}$ increases strongly with soil moisture heterogeneity (Fig 1c; $\chi^{2}=119$., $d f=9, P<0.0001$ ). Comparing the number of initiations in the lowest decile with the highest decile, $\mathrm{P}_{\mathrm{I}}$ increases by a factor of 2.5. This relationship is robust to the methods used to 95 compute the LSTA, but is sensitive to the choice of grid box size (Supplementary Fig. S1). In particular, the rise in $P_{1}$ with $\sigma_{\text {LSTA }}$ is maximised for grid boxes of lengths less than $30 \mathrm{~km}$, and becomes weak for grid boxes of $100 \mathrm{~km}$ or larger. The 
sensitivity of $P_{1}$ to $\sigma_{L S T A}$ under different thermodynamic conditions was also assessed (Fig. 1c) using the pressure difference between the level of free convection (LFC)

100 and the surface $\left(\mathrm{dp}_{\mathrm{LFC}}\right)$ computed from atmospheric analyses. When the atmosphere is conducive to deep convection ( $d p_{L F C}<210 \mathrm{hPa}$ ), values of $\mathrm{P}_{\mid}$are high, yet there is no clear increase with $\sigma_{\text {LSTA }}\left(\chi^{2}=8.32, d f=9, P=0.50\right)$. On the other hand, when convective inhibition is large $\left(\mathrm{dp}_{\mathrm{LFC}}>300 \mathrm{hPa}\right)$, the sensitivity to $\sigma_{\mathrm{LSTA}}$ is stronger, with a three-fold increase in $\mathrm{P}_{1}$ between the lowest and highest deciles. This strong

105 sensitivity under unfavourable large-scale atmospheric conditions implies that mesoscale soil moisture patterns trigger MCS which would not otherwise occur.

Mesoscale flux variability can originate from fixed landscape features as well as transient soil moisture patterns. The impact of these fixed features on MCS initiation was quantified using the standard deviation in the wet season mean LST ( $\sigma_{\text {LST }}$; Fig

1101 1). Grid boxes with sub-grid variations in topographic height exceeding $250 \mathrm{~m}$ were excluded from this calculation to avoid the well-known orographic effect on initiation. Whilst large values of $\sigma_{L S T}$ are less common than for $\sigma_{\text {LSTA }}$ in the study region, the relationships with $\mathrm{P}_{\mathrm{I}}$ are consistent for both fixed and transient heterogeneity (Figs 1c and $1 \mathrm{~d}$ ). The highest values of $\sigma_{\mathrm{LST}}$ were found over crop/forest areas in the south ${ }^{25}$,

115 and rocky areas associated with the Continental Terminal in the north.

The mean mesoscale structure of the LSTA field was determined by compositing the 3765 initiations relative to the low-level wind direction provided by atmospheric analyses (Fig.2a). This indicates favoured initiations within an elliptical pattern of positive LSTA values aligned with the background wind. Notable negative gradients 120 in the composite-mean LSTA are evident about $10 \mathrm{~km}$ from the initiation point in the down-wind and both cross-wind directions, corresponding to transitions to wetter soil. The composite soil moisture field from passive microwave is consistent with the 
LSTA field, although rather poorly resolved by comparison. To assess the preferred surface length scales, we performed a wavelet analysis on along-wind LSTA transects for every initiation. The average of these wavelets reveals strong variability on wavelengths of 20-75 km centred 0-10 km downwind of initiation (Fig 2b).

We further examined the likelihood of finding strong LSTA gradients $10 \mathrm{~km}$ downwind of initiation in each case and compared this with the distribution of LSTA gradients found by random sampling in the region (see Methods). The distribution in

130 the initiation sample is shifted to the left relative to the control (Fig.3). We calculated the LSTA gradient intervals corresponding to the first and central deciles $(0-10 \%$ and $45-55 \%$, respectively) of the control sample, which by definition are observed equally frequently. Convective initiations within the lowest interval occur 2.0 times more frequently than in the central interval. Thus, initiations are twice as likely over strong

135 LSTA gradients compared to uniform surface conditions (the lowest and central intervals respectively). Furthermore, we found that $37 \%$ of all the initiations occurred over moderately strong negative gradients $(<-3.2 \mathrm{~K} / 100 \mathrm{~km})$, corresponding to the first quartile of the control sample. This enhancement of initiations is equivalent to one in 8.3 of all MCS in the dataset.

140 The feedback is evident throughout the wet season, with differences in the distributions significant at $\mathrm{P}<0.0001$ for the 4 individual months as well as for the wet season mean (Supplementary Fig.S4). However, the effect is most pronounced in June and weakest in August. Two factors are likely to determine this seasonality. During the core monsoon period (July/August), the LFC tends to be lower, a regime

145 where convective sensitivity to the surface is weaker (Fig. 1). Secondly, spatial contrasts in fluxes tend to weaken as the season progress, since the developing vegetation can maintain transpiration rates over dry spells ${ }^{8}$. 
Modelling studies have shown ${ }^{26}$ that convection is favoured over dry soils, but close to negative upwind gradients in sensible heat flux. This preferred configuration occurs because convergence is maximised where the large-scale wind opposes the shallow surface-induced flow, as summarised in Fig 4. Strong evidence that such soil moisture-induced circulations do favour storm initiation is provided by our results, and in particular, the composite surface structure depicted in Fig 2a.The preferred initiation point in our observations is consistent with model studies, i.e. just upwind of 155 a dry-wet surface transition.

This study shows that soil moisture heterogeneity on scales of $10 \mathrm{~s} \mathrm{~km}$ has a pronounced impact on rainfall at the larger scale in the Sahel. This upscaling occurs because, once the convective instability has been released, the MCS expands and propagates typically hundreds of kilometres. The new soil wetness patterns

160 produced by an MCS in turn increase the probability of another MCS in the following day or two. We estimate spatial variability in LSTA on the day following a storm to be increased from 1.0 to $1.6 \mathrm{~K}$ (Supplementary Fig. S3), leading to positive feedback on the MCS scale of $100 \mathrm{~s} \mathrm{~km}$. On the other hand, considering smaller scales of several $10 \mathrm{sm}$, the feedback is negative due to preferred triggering over dry soils.

165 The observed relationships between convective initiation and soil moisture patterns presented here shed new light on land-atmosphere coupling mechanisms in the real world. Though focused on the Sahel, the conclusions are likely to be relevant for many semi-arid regions, particularly in the tropics, where a short growing season is driven by the seasonal migration of the ITCZ. It is important to note that the feedbacks highlighted here occur on length scales which are not represented in current climate models, though their effects have large scale consequences. This 
raises questions about the sensitivity of climate models to soil moisture, and their predictions for future rainfall changes in the semi-arid tropics.

\section{Methods Summary}

175 We used thermal infra-red brightness temperature data from the $10.8 \mu \mathrm{m}$ channel on the Meteosat Second Generation series of satellites, available every 15 minutes at a spatial resolution $\sim 3 \mathrm{~km}$. We adopted the widely used threshold of $-40^{\circ} \mathrm{C}$ to denote cold cloud. An MCS was defined as an area of contiguous cold cloud exceeding $5000 \mathrm{~km}^{2}$. When an MCS was found which did not overlap with an MCS in the

180 previous time step, we tracked the cold cloud system back in time and space to its origins. Provided the first cold pixel occurred a maximum of 3 hours prior to the areal MCS threshold being crossed, and that it did not overlap with other MCS during that time, we defined the location of that first cold pixel to be the initiation point of the MCS. The results of our simple MCS detection algorithm were very similar to those

185 produced by a more complex tracking method ${ }^{27}$.

To calculate values of LSTA, we applied a cloud screening to the LST data ${ }^{13}$. We then computed a mean diurnal cycle based on all remaining data within a period of 21 days, centred on the day in question. Daily LSTA were determined by averaging the diurnal LST anomalies between 8 and 16UTC.

190 We used operational analyses from the European Centre for Medium Range Weather Forecasting for an estimate of synoptic conditions in the vicinity of MCS initiations. These data have a horizontal resolution of $0.35^{\circ}$ and comprise 50 vertical levels between the surface and $15 \mathrm{~km}$. The low level wind data was taken at $10 \mathrm{~m}$ above the ground from the 12UTC analyses, whilst the LFC was estimated at 06UTC 195 by lifting a parcel from about 50m above the ground. 
The confidence limits in Figure 1 were calculated based on a binomial distribution, where the probability of initiation was determined from the observations prior to binning. $\mathrm{A} \chi^{2}$ test was performed on the histograms in Fig. $1 \mathrm{c}$ under the null hypothesis that they were uniform. In Figure 3, we sampled the background

200 distribution of LSTA gradients on the day in question using 44 regularly spaced locations around each initiation point. These points occurred every $0.5^{\circ}$ within a $4^{\circ} \mathrm{x}$ $2^{\circ}$ lattice. This sampling strategy ensured that the gradients were appropriately weighted by latitude and day of year. Only soil moisture data from descending orbits of the Aqua satellite were used (overpass time around 0130 UTC), and data

205 excluded where rain exceeding $2 \mathrm{~mm}$ was detected in the TRMM3B42 dataset for the hours between the overpass and midday.

Supplementary Information available online.

Author Contributions CT and FG conceived the study and wrote the paper, AG analysed the LST data, CT developed the cloud tracking, FG determined the 210 atmospheric sensitivities, PH devised statistical tests, RE and FC evaluated the tracking and MK performed the wavelet analysis. All authors discussed the results and commented on the manuscript. 


\section{Figures}

215 Figure 1 Sensitivity of MCS initiation to land surface properties. Total number and probability of initiations as a function of (a) volumetric soil moisture (b) volumetric soil moisture anomaly compared to the mean over $1.75 \times 1.75^{\circ}$, (c) $\sigma_{\text {LSTA, }}$, and (d) $\sigma_{\text {LST. }}$. Each horizontal line represents one decile, a circle indicates the median, and shading delimits the $95 \%$ confidence limits. In (c) and (d), the

220 probability of initiation is also shown for sub-samples containing grid points with $\mathrm{dp}_{\mathrm{LFC}}<210 \mathrm{hPa}$ (blue line) and $\mathrm{dp}_{\mathrm{LFC}}>300 \mathrm{hPa}$ (orange line). The relationships in (c) and (d) are independent as $\sigma_{\text {LSTA }}$ is not correlated with $\sigma_{\text {LST }}(r=0.018, n>50,000)$.

a

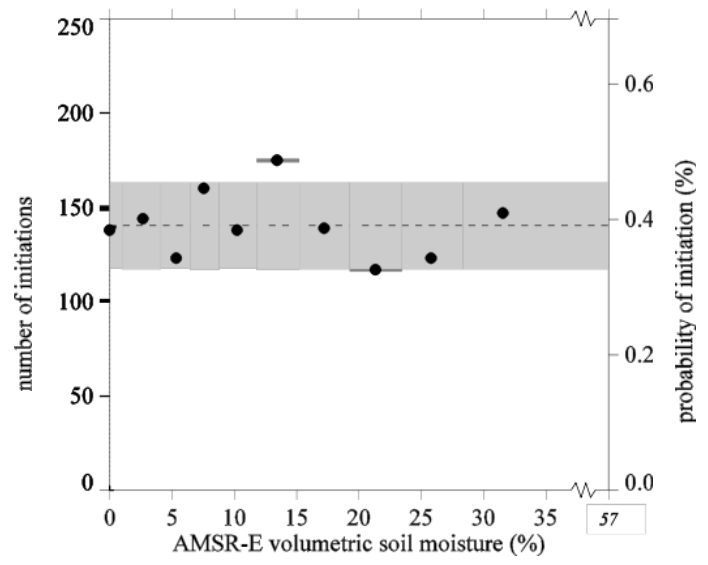

C

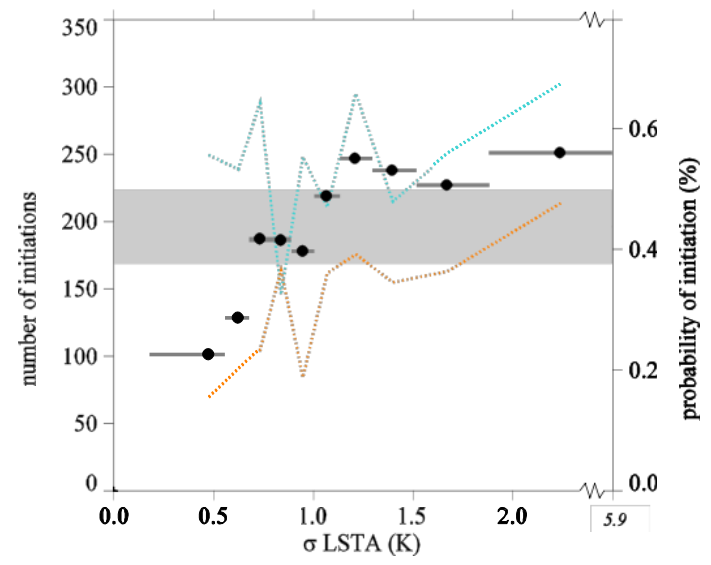

b

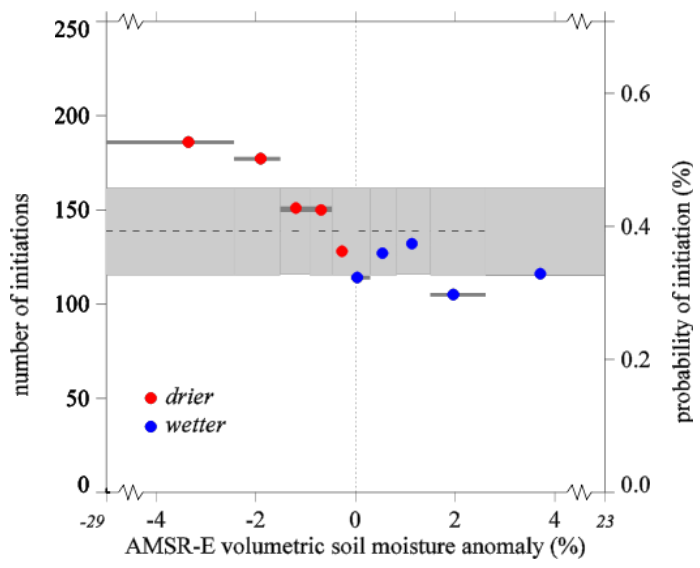

d

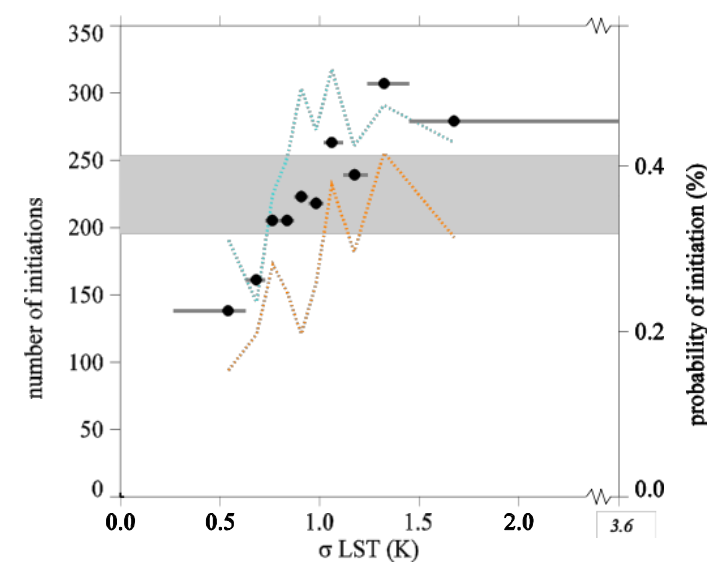


Figure 2 Mesoscale surface variability around initiation point. (a) Composite

225 LSTA (K; shading) and volumetric soil moisture anomalies from the seasonal mean (\%; contours). For clarity, the spatial mean LSTA was removed from each event. Anomalies larger than $+/-0.2 \mathrm{~K}$ are statistically different from 0 (2-tailed ttest, $P<0.01$ for $n=2439$ ). (b) Weighted wavelet Z-transform ${ }^{28}$ computed from LSTA transects in the along-wind direction. The shading denotes the difference in the mean between

230 the initiation and a control (non-initiation) dataset. Within the black contour line, the increase in amplitude between the two datasets is significant $(P<0.01)$ according to a 1-tailed t-test.
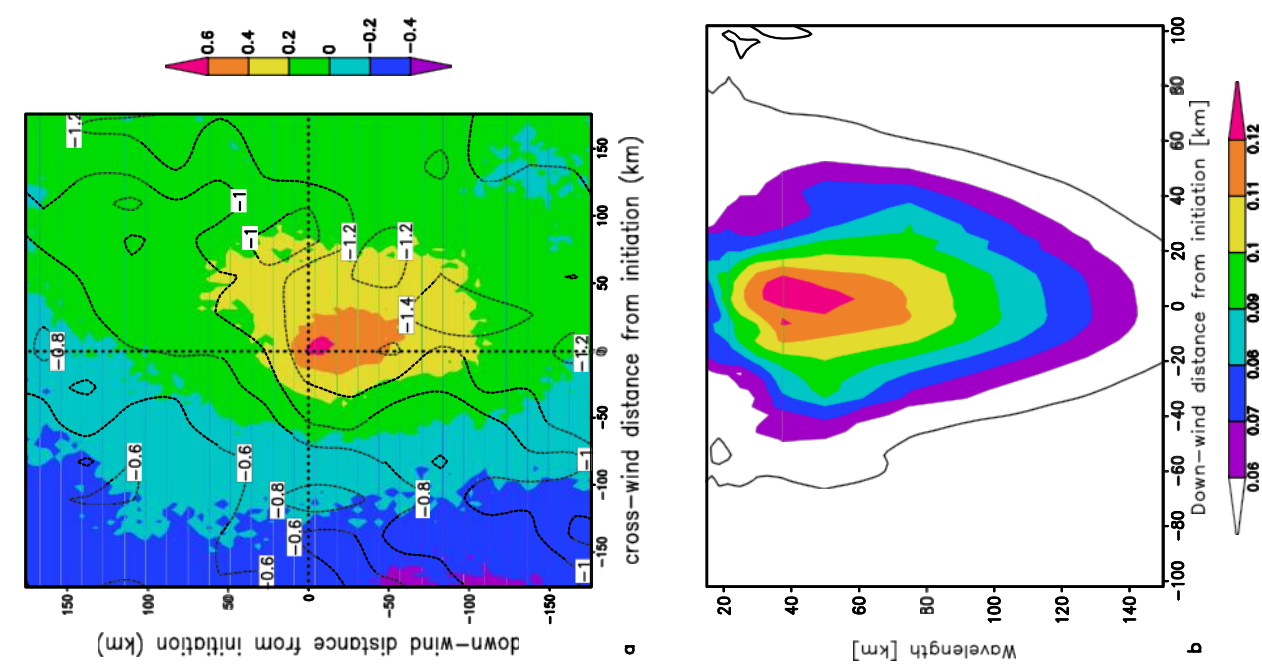
Figure 3. Distribution of LSTA gradients associated with MCS initiations. The 235 frequency of along-wind LSTA gradients $(\mathrm{K} / 100 \mathrm{~km})$ located $10 \mathrm{~km}$ downstream of the initiation point (black stepped line). The expected frequency of gradients found by sampling across the region (see Methods) is shown for comparison (grey line) with areas of enhanced (reduced) probability of initiation shaded in orange (grey).

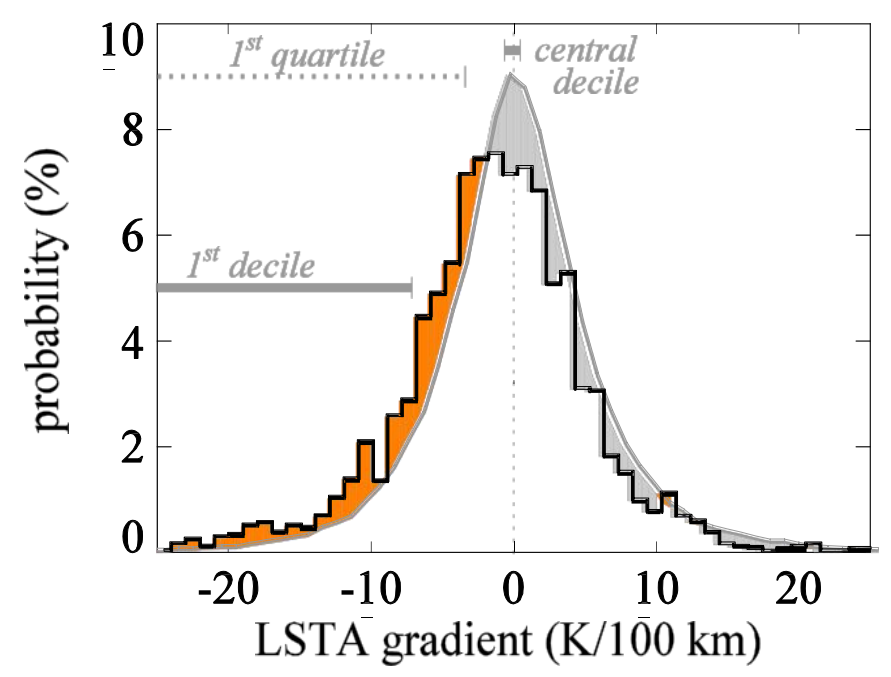




\section{Figure 4 Schematic depicting the impact of soil moisture heterogeneity on}

convective initiation. Idealised soil moisture-induced flows (blue arrows) under light synoptic winds create an ascent region where the shallow, strong current opposes the mean wind (adapted from Fig. 7 in ${ }^{25}$ ). The preferred location for convective

245 initiation in this study coincides with the ascent region induced by the heating gradient at the downwind edge of the dry patch. Additional convergence over the dry patch is provided by a deep, weaker current at its upwind edge, and cross-wind gradients in soil moisture (evident in Fig 2a but not shown here).

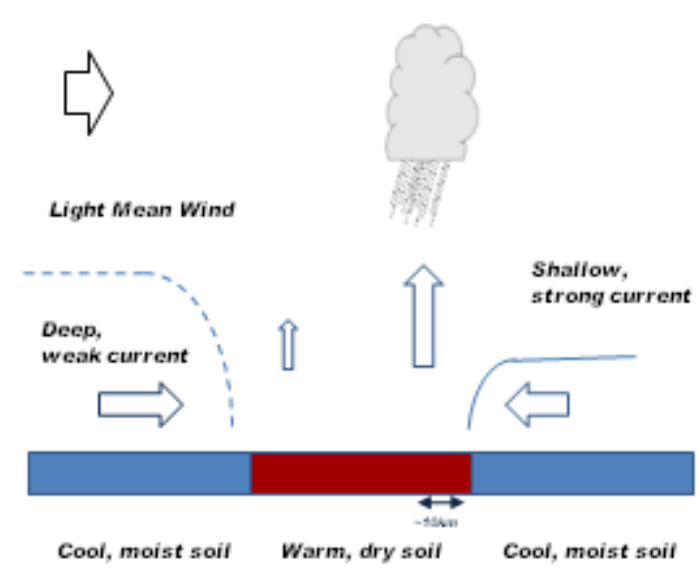

Author Information Correspondence and requests for materials to $\underline{\mathrm{cmt} @ \text { ceh.ac.uk }}$

Acknowledgements Based on a French initiative, AMMA was built by an international scientific group and is currently funded by a large number of agencies, especially from France, the UK, the US and Africa. The authors were funded by the

255 European Community's Sixth Framework Research Programme and the UK NERC project NE/B505597/1. We would like to thank Doug Parker and Jan Polcher for many valuable discussions on this topic. We also thank LandSAF for the provision of 
land surface temperature data, EUMETSAT for cloud data, and Richard de Jeu for soil moisture retrievals.

\section{References}

$1 \quad$ Koster, R. D. et al. Regions of strong coupling between soil moisture and precipitation. Science. 305, 1138-1140 (2004).

2 Hastenrath, S., Climate dynamics of the tropics. (Kluwer Eds, New York, 1995).

2653 Ganopolski, A. et al. The influence of vegetation-atmosphere-ocean interaction on climate during the mid-Holocene. Science. 280, 1916-1919 (1998).

$4 \quad$ Zeng, N., Neelin, J. D., Lau, K. M. \& Tucker, C. J. Enhancement of interdecadal climate variability in the Sahel by vegetation interaction. Science. $270 \quad 286,1537-1540$ (1999).

5 Giannini, A., Saravanan, R. \& Chang, P. Oceanic forcing of Sahel rainfall on interannual to interdecadal time scales. Science. 302, 1027-1030 (2003). Taylor, C. M. \& Ellis, R. J. Satellite detection of soil moisture impacts on convection at the mesoscale. Geophys. Res. Lett. 33, L03404 (2006).

2757 Taylor, C. M. \& Lebel, T. Observational evidence of persistent convectivescale rainfall patterns. Mon. Weather Rev. 126, 1597-1607 (1998). Kohler, M., Kalthoff, N. \& Kottmeier, C. The impact of soil moisture modifications on $\mathrm{CBL}$ characteristics in West Africa: A case-study from the AMMA campaign. Q. J. R. Meteorol. Soc. 136, $442-455$ (2010).

2809 Mathon, V., Laurent, H. \& Lebel, T. Mesoscale convective system rainfall in the Sahel. J. Appl. Meteorol. 41, 1081-1092 (2002). 
Lebel, T., Taupin, J. D. \& D'Amato, N. Rainfall monitoring during HAPEX-

Sahel: 1. General rainfall conditions and climatology. J. Hydrol. 189, 74-96 (1997).

Owe, M., de Jeu, R. \& Holmes, T. Multisensor historical climatology of satellite-derived global land surface moisture. Journal of Geophysical Research-Earth Surface. 113 (2008).

Trigo, I. F., Monteiro, I. T., Olesen, F. \& Kabsch, E. An assessment of remotely sensed land surface temperature. J. Geophys. Res. - Atmospheres. 113 (2008).

Stewart, D. J., Taylor, C. M., Reeves, C. E. \& McQuaid, J. B. Biogenic nitrogen oxide emissions from soils: impact on NOx and ozone over west Africa during AMMA (African Monsoon Multidisciplinary Analysis) observational study. Atmospheric Chemistry and Physics. 8, 2285-2297 (2008). Taylor, C. M., Harris, P. P. \& Parker, D. J. Impact of Soil Moisture on the Development of a Sahelian Mesoscale Convective System: A Case Study from the AMMA Special Observing Period. Quart J Roy Meteorol Soc. 136, 456-470 (2010). Mesoscale Atmospheric Circulations Induced By Soil Moisture. Geophys. Res. Lett. 34, L15801 (2007). Gantner, L. \& Kalthoff, N. Sensitivity of a modelled life cycle of a mesoscale convective system to soil conditions over West Africa. Q. J. R. Meteorol. Soc. 136, 471-482 (2010). 
Gaertner, M. A., Dominguez, M. \& Garvert, M. A modelling case-study of soil moisture-atmosphere coupling. Q. J. R. Meteorol. Soc. 136, 483-495 (2010). Chen, F. \& Avissar, R. Impact of land-surface moisture variability on local shallow convective cumulus and precipitation in large-scale models. J. Appl. Meteorol. 33, 1382-1401 (1994).

Baidya Roy, S., Weaver, C. P., Nolan, D. S. \& Avissar, R. A preferred scale for landscape forced mesoscale circulations? J. Geophys. Res. Atmospheres. 108 (2003). Weaver, C. P. Coupling between large-scale atmospheric processes and mesoscale land-atmosphere interactions in the US Southern Great Plains during summer. Part I: Case studies. J. Hydromet. 5, 1223-1246 (2004). Pielke, R. A. et al. Nonlinear influence of mesoscale land-use on weather and climate. J. Climate 4, 1053-1069 (1991). Mathon, V. \& Laurent, H. Life cycle of Sahelian mesoscale convective cloud systems. Q. J. R. Meteorol. Soc. 127, 377-406 (2001).

Carleton, A. M. et al. Summer season land cover - convective cloud associations for the Midwest US "Corn Belt". Geophys. Res. Lett. 28, 16791682 (2001).

Wang, J. F. et al. Impact of deforestation in the Amazon basin on cloud climatology. Proc. Natl. Acad. Sci. U. S. A. 106, 3670-3674 (2009). Garcia-Carreras, L. et al. Impact of mesoscale vegetation heterogeneities on the dynamical and thermodynamic properties of the planetary boundary layer. J. Geophys. Res. - Atmospheres. 115 (2010). 

for the Modification of Convective Cloud Distributions by Land SurfaceInduced Flows? J. Atmos. Sci. 68, 619-634 (2011). Morel, C. \& Senesi, S. A climatology of mesoscale convective systems over Europe using satellite infrared imagery. I: Methodology. Quart J Roy Meteorol Soc. 128, 1953-1971 (2002).

33528 Foster, G. Wavelets for period analysis of unevenly sampled time series. Astronomical Journal. 112, 1709-1729 (1996). 

patterns

Christopher M. Taylor ${ }^{\mathrm{a}}$, Amanda Gounou ${ }^{\mathrm{b}}$, Françoise Guichard ${ }^{\mathrm{b}}$, Phil P. Harris ${ }^{\mathrm{a}}$, Richard J. Ellis ${ }^{\mathrm{a}}$, Fleur Couvreux ${ }^{\mathrm{b}}$, Martin De Kauwe ${ }^{\mathrm{c}}$.

${ }^{a}$ Centre for Ecology and Hydrology, Wallingford, U.K.

${ }^{\mathrm{b}}$ CNRM (CNRS and Météo-France), Toulouse, France

${ }^{\mathrm{c}}$ Macquarie University, Sydney, Australia

\section{Supplementary material}

1. The sensitivity of the increase in $P_{I}$ with $\sigma_{L S T A}$ (Fig 1c) to the choice of grid box size is assessed by repeating the calculation for grid box sizes ranging from $0.08^{\circ}$ to $2.0^{\circ}$ (approximately 9 to $220 \mathrm{~km}$ ). The results are shown in Figure S1 in terms of the frequency of MCS initiation in the $10^{\text {th }}$ decile divided by the frequency in the first decile.

\section{Figure S1}

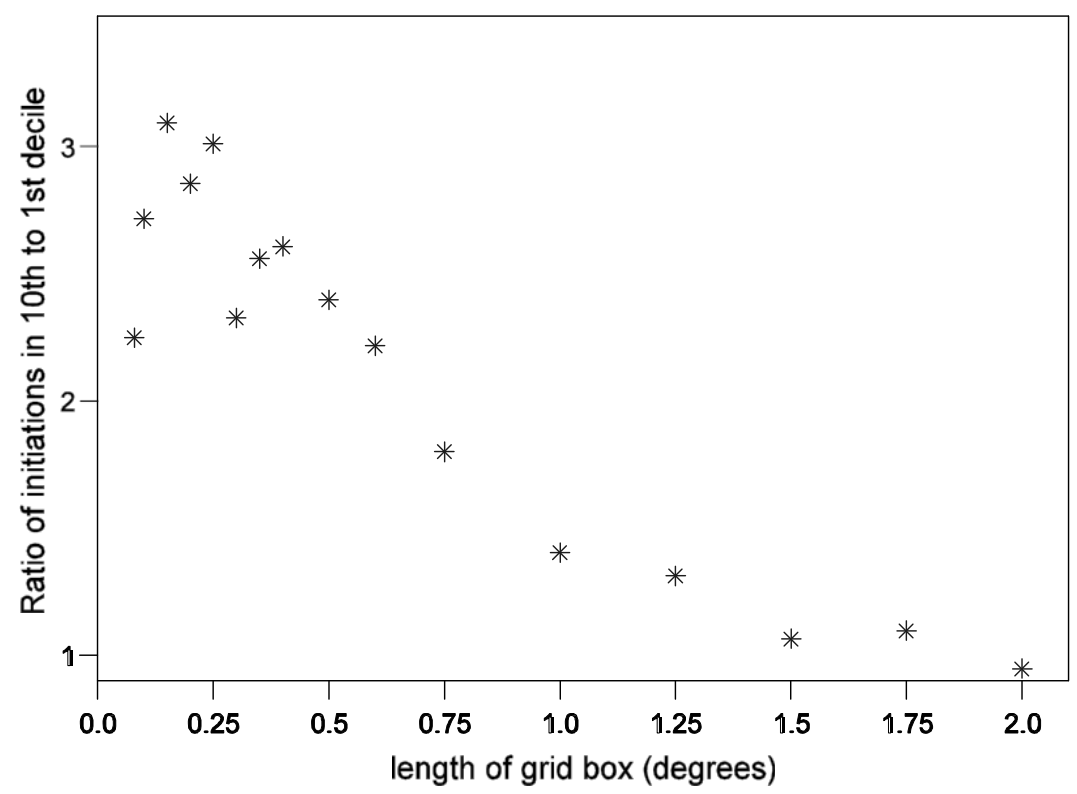


2. The sensitivity of the increase in $P_{I}$ with $\sigma_{L S T A}$ (Fig 1c) to the choice of time period used to compute the LST anomalies is shown in Figure S2. Replacing a 21 day running mean centred on the day in question with the seasonal mean increases values of $\sigma_{\text {LSTA }}$ generally. However, the underlying relationship between $P_{1}$ with $\sigma_{\text {LSTA }}$ remains. This confirms that variability in the LSTA field on a particular day is dominated by soil moisture on that day.

\section{Figure S2}

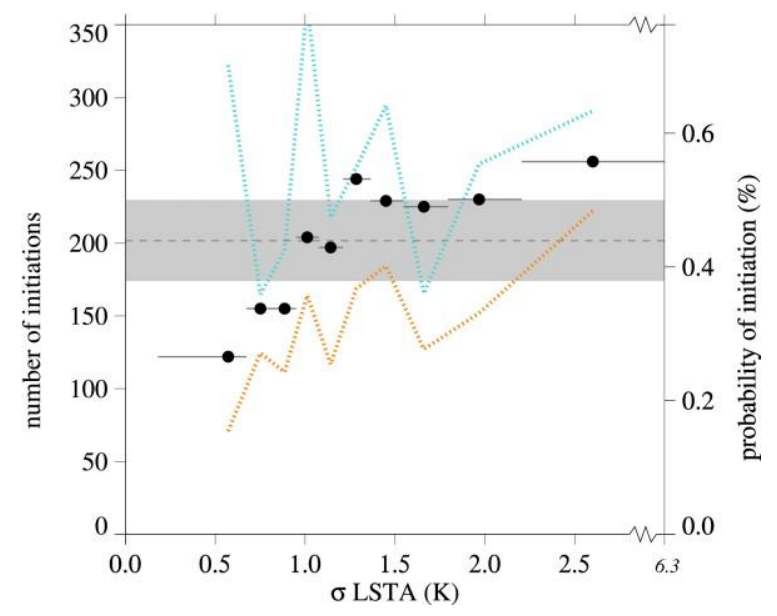


3. The relationship between our tracked MCS and LSTA on the following day is illustrated in Figure S3. The northern edge of all the MCS tracks with a lifetime of at least 3 hours was identified and used to composite the available LSTA data on the following day with respect to this cold cloud edge. The calculation was performed

370 over grid boxes of $0.35 \times 0.35^{\circ}$, and both the mean and standard deviation values of LSTA are shown as a function of distance from the edge. To minimise the impact of smaller, possibly rain-bearing cold clouds on the dry side of the track, we excluded all data there where cold cloud is detected in the 24 hour period to $12 Z$. The results show a decrease in LSTA over the tracked MCS $\sim 1.5^{\circ} \mathrm{C}$ (mean value between 0 and

$375-100 \mathrm{~km}$ ), as compared to the adjacent dry area (mean between 0 and $+100 \mathrm{~km}$ ). The mean value of $\sigma_{\text {LSTA }}$ over the storm track increases by $0.6^{\circ} \mathrm{C}$ compared to the dry area. This heterogeneity can feed back on the initiation of new MCS.

\section{Figure S3}

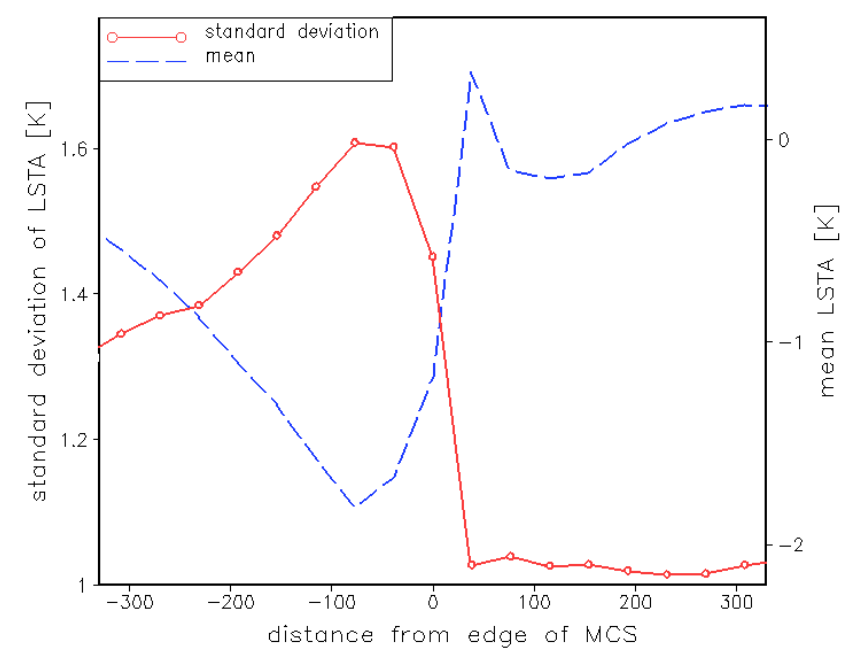


4. As for Figure 3, but based on data by month: (a) June, (b) July, (c) August and (d) September. The total number of inititations ( $N_{\text {init }}$ ), and the percentage of those initiations which fall within the lower quartile $\left(\mathrm{P}_{25}\right)$ of LSTA gradients in the background sample are: (a) $\mathrm{N}_{\text {init }}=604, \mathrm{P}_{25}=40.1 \%$, (b) $\mathrm{N}_{\text {init }}=619, \mathrm{P}_{25}=33.4 \%$, (c) $385 \mathrm{~N}_{\text {init }}=550, \mathrm{P}_{25}=34.2 \%$ and (d) $\mathrm{N}_{\text {init }}=528, \mathrm{P}_{25}=38.8 \%$.

\section{Figure S4}

(a)

(b)
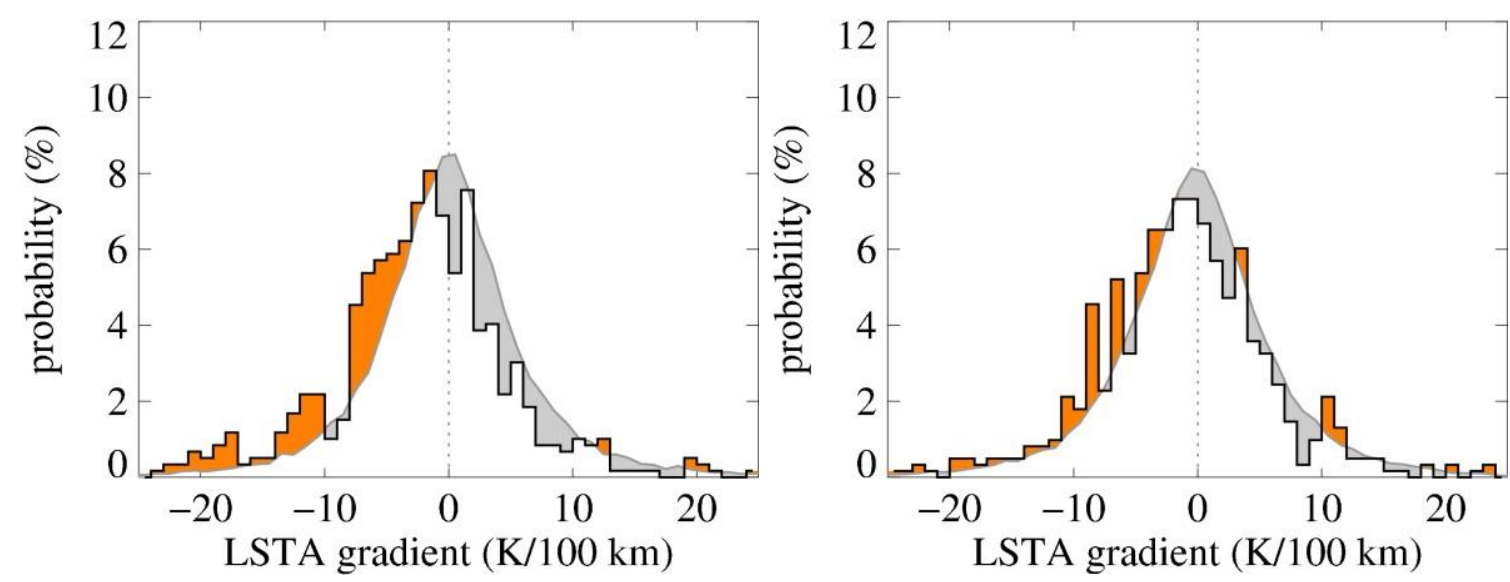

(c)

(d)
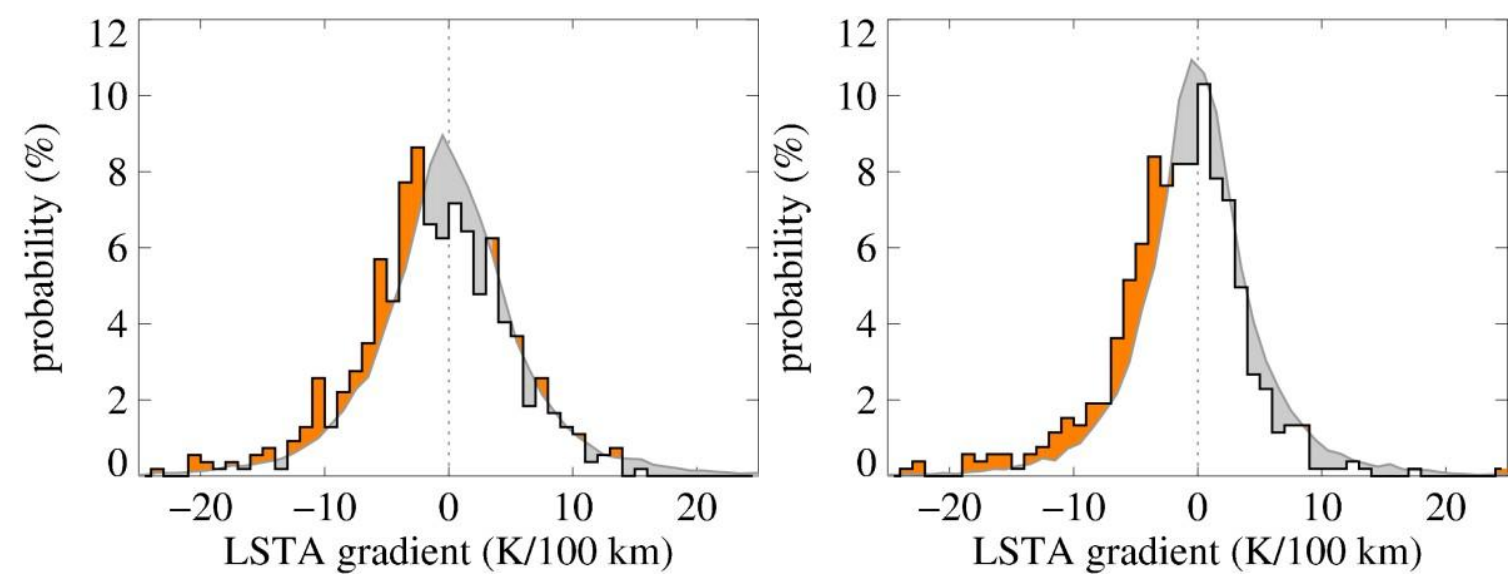
5. In this study we use two independent datasets to characterise areas of wet soil. Direct estimates of soil moisture are available from AMSR-E, but the footprint of this sensor is too large to adequately resolve the key surface features implicated in the initiation of MCS ( 10-40 km). On the other hand, LSTA data provide a qualitative indication of soil moisture at $3 \mathrm{~km}$ resolution. In particular, mesoscale structures in LSTA maps can provide an accurate mapping of areas with contrasting soil moisture ${ }^{13-15}$. By focusing on mesoscale variability rather than its absolute values, the impacts on LSTA of large-scale atmospheric forcing (wind speed, atmospheric water 400 vapour and aerosol), are minimised.

Figure S5a compares measures of spatial variability on a day-to-day time scale from the 2 data sources. These are quantified using the standard deviations of soil moisture and LSTA at $0.25^{\circ}$ resolution ( $\sigma_{\mathrm{Sm}}$ and $\sigma_{\mathrm{LSTA} 25}$ respectively) within boxes of $1.75 \times 1.75^{\circ}$, centred on $15^{\circ} \mathrm{N}$. The shaded contours denote the frequency with which binned values of $\sigma_{\text {LSTA25 }}$ and $\sigma_{\mathrm{sm}}$ are found, and the line presents the mean $\sigma_{\text {LSTA25 }}$ for a given bin of $\sigma_{\mathrm{sm}}$. The figure illustrates that $\sigma_{\text {LSTA25 }}$ increases with $\sigma_{\mathrm{sm}}$ over the full range of $\sigma_{\mathrm{sm}}$. In particular, when antecedent MCS induce high values of $\sigma_{\mathrm{sm}}$ (e.g. $>4 \%$ ), these tend to be accompanied by high values of $\sigma_{\text {LSTA25. }}$. This supports our use of LSTA to quantify spatial variability in soil moisture.

410 Figure S5b illustrates the relationship between mean soil moisture at the $0.25^{\circ}$ scale from AMSR-E and sub-grid soil moisture variability, inferred from the standard deviation of LSTA data at the $3 \mathrm{~km}$ scale $\left(\sigma_{\text {LSTA }}\right)$. These data are sampled from across the domain. As mean soil moisture increases from 0 to $10 \%$, so does $\sigma_{\text {LSTA. }}$. This correponds to a regime where surface fluxes are strongly water-limited and any

415 rain creates contrasting patches of wet and dry soil. As soil moisture increases further, $\sigma_{\text {LSTA }}$ becomes smaller. This is partly due to a weakened sensitivity of evaporation to soil moisture in wetter soils, coupled with a decreased likelihood of very dry conditions within the grid box. In addition, wetter soils in our dataset are associated with more densely vegetated surfaces. These have a higher roughness 420 length, which in turn will reduce variability in LST, and thus contribute to the observed negative trend.

\section{Figure S5}

(a)

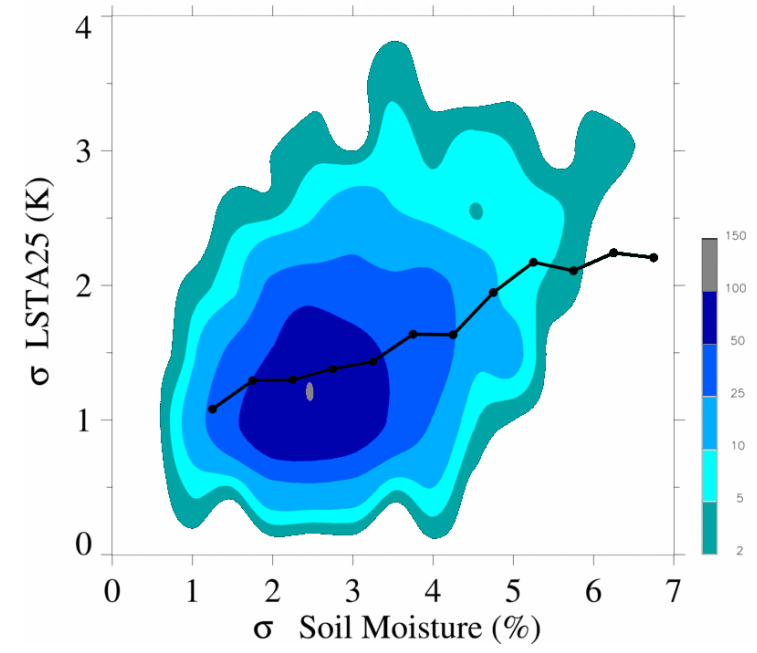

(b)

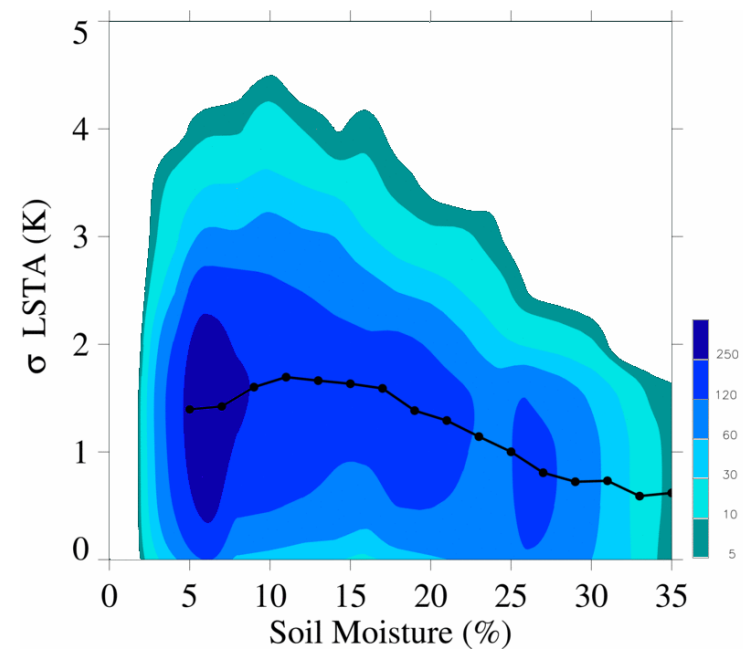

